DOI: https://doi.org/10.30749/2594-8261.v3n3p176-189

\title{
ORIGEM DO CONCEITO DE CLASSIFICAÇÃO E SUA APLICABILIDADE NOS DOCUMENTOS DE ARQUIVO
}

\section{THE ORIGIN OF THE CLASSIFICATION CONCEPT AND ITS APPLICABILITY IN FILE DOCUMENTS}

\section{Fernanda Maria de Andrade Ferreira*}

Resumo: $O$ objetivo deste trabalho é buscar a origem e o desenvolvimento da construção dos planos de classificação e como estes se estabeleceram na literatura e no pensamento arquivístico. O foco se atém na identificação de como, a partir da origem da classificação, a gestão de documentos foi construída para um saber dos documentos de arquivo. Busca-se, ainda, reconhecer os princípios do respeito aos fundos e da ordem original, como fundamentos preciosos à classificação em arquivístico. Procura-se identificar a gênese dessa disciplina e as repercussões da sua prática.

Palavras-chave: Arquivística. Classificação. Gestão de documentos.

Abstract: The purpose of this paper is to search for the origin and development of the construction of the classification plans and how they were established in the literature and archival thinking. The focus is on identifying how, from the origin of classification, document management was built to a knowledge of archival documents. It also seeks to recognize the principles of respect for funds and the original order as precious foundations for archival classification. The attempt is to identify the genesis of this discipline and the repercussions of its practice.

Keywords: Archiving. Classification. Document management.

\footnotetext{
Mestre Profissional em Gestão de Documentos e Arquivos ? MPGA 2018- pelo Programa de PósGraduação de Documentos e Arquivo (PPGARQ).
} 


\section{INTRODUÇÃO}

Ao identificar a classificação de documentos como a atividade âmago da gestão de documentos, visto que há uma carência na arquivística de uma política teórico-metodológica consolidada para a construção dos planos de classificação, julga-se necessário buscar na origem da classificação o desenvolvimento do conceito e como este se estabeleceu na literatura e no pensamento arquivístico.

O foco não se atém à investigação das bases teóricas e metodológicas do processo classificatório, tampouco apresenta como ele se aplica à gestão de documentos, mas sim identifica como, a partir da origem da classificação, esta foi construída para um saber dos documentos de arquivo. Ao reconhecer os princípios de respeito aos fundos e da ordem original, como fundamentos preciosos à classificação em arquivística, trata-se, neste texto, de aprofundar o tema ao identificar-se o seu nascimento e as repercussões na prática dessa disciplina, além do que se configuram como os norteadores deste processo.

\section{A CONSTRUÇÃO DO CONCEITO DE CLASSIFICAÇÃO}

$\mathrm{O}$ ato de classificar parece estar ligado a todas as atividades do homem, das mais simples às mais complexas. Entende-se que, sem a classificação, a evolução humana não seria possível e que seu conceito também é apropriado de forma inconsciente. Para Kumar (1988, p. 1) a classificação está em todos os momentos da vida humana. Diariamente, em grande extensão, as pessoas classificam sem criar consciência do ato. Segundo Sousa (2004, p. 78) o fato da inconsciência do ato é um indício da natureza fundamental do processo de classificação. E mais: "sem classificação não poderia haver nenhum pensamento humano, ação e organização que conhecemos. A classificação transforma impressões sensoriais isoladas e incoerentes em objetos reconhecíveis e padrões recorríveis".

A classificação é considerada uma das habilidades mais básicas do conhecimento humano pois, segundo Pombo (1998, p. 1-2), nada nos parece mais "natural", óbvio e indiscutível que as classificações dos entes, dos fatos e dos acontecimentos. A classificação "natural" a que a autora se refere acontece a partir 
do nascimento do ser humano, consideradas as classificações primordiais intrínsecas à sua formação. Elas são, conforme Foucault (1995, p. 10), os "códigos ordenadores" da nossa cultura. São códigos fundamentais de todas as culturas, não no sentido vulgarmente sociológico e relativista de instituições que variam de uma idade para outra, de uma geografia para outra, mas como aqueles que "fixam logo à entrada, para cada homem, as ordens empíricas com que ele terá que lidar e em que há de encontrar" (FOUCAULT, 1995), solos epistêmicos "onde os próprios conhecimentos enraízam a sua possibilidade" (FOUCAULT, 1995) e onde o olhar minucioso, descritivo, hierarquizador e relacional que torna possível a constituição de todos os saberes encontra o seu próprio princípio de instituição.

Fernandez (1979, p. 256-257) esclarece que a criança, desde o instante de seu nascimento, depara-se com o novo e desconhecido, e a sua sobrevivência está diretamente relacionada a esse mundo. Num primeiro momento, ela se faz exclusivamente por meio dos sentidos. Essas primeiras experiências são impressões sensoriais, isoladas e incoerentes de visão, olfato, tato e paladar. As impressões vão sendo guardadas na memória e estarão prontas para serem utilizadas como fontes de informação. Por meio de associações de ideias, as impressões sensoriais são transformadas em objetos reconhecíveis e padrões recorríveis que o ser humano classifica.

Há três estágios na construção do conceito de classificação. Na primeira fase, ainda na infância, a criança cria uma coleção de figuras e consegue apenas relacionar as que contêm semelhanças entre elas. Atrelada ao sensível, "procede gradualmente, esquecendo o que acaba de fazer e não prevendo o que se seguirá: alinha, por exemplo, o conjunto dos elementos dados, alterando a cada momento o critério que determina as suas aproximações sucessivas, ou, constrói, então, um objeto coletivo ou complexo justapondo os elementos, sem plano nem coerência". (SOUSA, 2004).

A noção de classe surge gradualmente na coordenação progressiva da extensão e da compreensão, na introdução de procedimentos retroativos, ou seja, a assimilação deixa de ser sensoriomotora - período da vida entre o nascimento e os dois anos de idade em que se destaca a construção da noção do eu - criando uma visão de extensão ao mundo. 
$\mathrm{Na}$ segunda fase, os conjuntos se formam nas semelhanças, perduram justapostos sem ainda serem inseridos nas classes mais gerais. Por um bom tempo, há uma oscilação do método ascendente com o descendente, ou seja, a reunião de pequenos grupos semelhantes em grupos mais vastos ou por divisões no interior do conjunto tomado na sua totalidade.

$\mathrm{Na}$ última fase, as classificações aparecem como uma manifestação do pensamento. Cria-se a noção de qualidade, quantidade, relações e entidade. $\mathrm{Na}$ elaboração da classificação atinge-se a noção de hierarquização e na inclusão encontra-se a categoria das classificações.

Admite-se que a classificação é uma atividade complexa, dinâmica e radical, sendo possível identificá-la em dois grandes níveis: classificação dos seres e classificação dos saberes. O primeiro nível corresponde às áreas da biologia, geologia, cosmologia, antropologia e psicologia. Primeiramente desenvolvida, por vezes de forma obsessiva, no Renascimento e no século XVII, é no século XIX que "a classificação das ciências é então atividade filosófica autônoma, determinada por razões teóricas, especulativas, de conquista de uma mais rica compreensão das relações entre os saberes". (POMBO, 1998, p. 3). O segundo nível corresponde à classificação dos livros e das informações, um novo campo de estudo científico que objetiva a criação de sistemas de classificação e que, mesmo sendo de interesse direto dos classificacionistas, solicita a colaboração dos filósofos para tornar-se uma ciência da classificação.

Segundo Pombo (1998, p. 4-5), as características gerais das classificações das ciências são: 1) supor um agente classificativo (ex. filósofo, cientista, educador, etc.); 2) possuir determinado mecanismo classificador; 3) supor um princípio de classificação; 4) perseguir uma multiplicidade de fins (pode ir do interesse especulativo à orientação normativa da atividade científica, à determinação de um programa de estudos ou organização de uma biblioteca); 5) buscar exercer sobre um conjunto de elementos finitos as ciências constituídas ou em vias de constituição; 6) construir-se no contexto das classificações precedentes, ou seja, integrar-se ao contexto das histórias das classificações das ciências; e 7) pressupor a existência de um produto externo da atividade classificadora (estrutura hierárquica, árvore genealógica, tábua de chavetas, entre outros). 
A classificação é uma escolha diante de outras classificações possíveis, reconhecendo na escolha adotada um conjunto de razões suficientes. É para tantos pontos de vista de representação e um grande número de sistemas de representação possíveis que se identifica a dualidade da naturalidade ou arbitrariedade da classificação. Naturalidade no sentido de que as afinidades tendem a reunir em classes as diversas formas de classificar e arbitrariedade por depender da escolha e/ou vontade de alguém para que se definam essas afinidades.

Reconhece-se a complexidade da formação desse conceito na ciência dos seres e a construção do conceito na ciência dos saberes, no que tange, especificamente para este trabalho, a classificação de documentos de arquivo. Pode-se também, dentro da classificação biológica, encontrar uma analogia com a classificação dos documentos. Na biologia nada tem sentido sem a evolução entre os seres vivos, há um vínculo conectado em que os próprios seres se classificam naturalmente pela seleção natural (Darwinismo); na arquivística nada tem sentido sem o vínculo arquivístico, a relação dos documentos entre si, pois que a classificação mantém e faz a "seleção natural", permitindo sua construção (evolução) de forma orgânica e natural.

Para Sousa (2004, p. 78-80) a Filosofia ocupa um espaço privilegiado na construção de um arcabouço teórico-metodológico no que tange ao encontro de bases científicas para a criação de sistemas de classificação. A partir do século XX, uma dessas bases passou a ser chamada Teoria da Classificação, mas, já em 1873, século XIX, nos Estados Unidos, surge com Melvil Dewey a primeira classificação bibliográfica de caráter universal. Não foi a primeira classificação a utilizar assunto na organização dos livros, mas foi o primeiro a atribuir símbolos (numéricos) na classificação.

Melvil Dewey (2003) elaborou perguntas que pudessem ter sido feitas para satisfazer sua curiosidade (necessidades informacionais) e assim dispor uma organização em que os livros de não ficção ficassem próximos na estante. $O$ bibliotecário dividiu o pensamento humano em dez classes principais: Generalidades; Filosofia e Psicologia; Religião; Ciências Sociais; Língua e Linguagem; Ciências Naturais; Ciências Aplicadas; Artes e Recreação; e Literatura. 
O autor Schellenberg (1980, p. 11), em um trecho de seu livro intitulado Arquivos modernos, princípios e técnicas, apresenta uma descrição de Dewey de como surgiu sua ideia para um novo sistema que propunha revolucionar a classificação dos livros. O autor afirma que a tese fundamental do sistema decimal de Dewey é a de que o conhecimento humano pode ser dividido em dez classes principais, cada uma das quais comportando a repartição sucessiva em seções e subseções de dez. As classes eram escritas com três algarismos. A grande parte das classes maiores dividia-se por critério puramente lógico, que consistia em decompor o todo nas partes e estas em partes menores ou, por outras palavras, em dividir sucessivamente uma ampla área de assuntos em áreas menores. Assim: 000 - GENERALIDADES; 100 - FILOSOFIA E PSICOLOGIA; 200 - RELIGIÃO; 300 CIÊNCIAS SOCIAIS; 400 - LÍNGUA E LINGUAGEM; 500 - CIÊNCIAS PURAS; 600 CIÊNCIAS APLICADAS; 700 - ARTES E RECREAÇÃO; 800 - LITERATURA; 900 GEOGRAFIA, HISTÓRIA E BIOGRAFIA.

Para Schellenberg (1980, p. 13), o sistema Dewey apresentado de forma simples e expansivo, representava vantagens, mas ao mesmo tempo fraquezas. $O$ autor entende que o conhecimento humano não é e nunca será definitivo e nem permanecerá satisfatório por um longo tempo. Pelo contrário, estará em constante expansão. Logo, nenhum conjunto de classes de dez, de vinte ou de qualquer outro número ajustar-se-ia às necessidades da classificação. Após o sistema de Dewey, surge na década de 1930 o sistema do matemático e bibliotecário indiano Shiyali Ramamrita Ranganathan.

Dahlberg (1979) reconhece que a abordagem ranganathiana era totalmente diferente das formas de classificação vistas antes. Embora já se pudesse observar que os sistemas de Dewey tinham uma abordagem combinatória e analítica, 0 sistema de Ranganathan divergia dos outros, acima de tudo pelo fato de que ele não usava classes preestabelecidas e prontas às quais os títulos tinham de ser relacionados, mas criava classes de livros somente no momento em que um livro era analisado segundo os elementos conceituais de seu assunto e sintetizado segundo as regras das fórmulas de facetas ligadas às disciplinas. Entre os novos conceitos e as inovações criadas por Ranganathan podem-se evidenciar dois pontos que podem ser considerados na contribuição para a moderna Teoria da Classificação. 
O indiano, em primeiro lugar, introduziu três níveis distintos com base no trabalho dos classificacionistas (criadores de sistemas de classificação) e os classificadores (os que classificam): Nível 1 - Plano de ideia (conceitos); Nível 2Plano verbal (expressão verbal dos conceitos); e Nível 3 - Plano Notacional (representação dos conceitos em formas de sinais - letras e números).

Diferentemente da Biblioteconomia, na Arquivologia, o reconhecimento da importância da função Classificação - atividade que compõe a gestão dos documentos de arquivo - não garantiu um aprofundamento e um cuidado maior com a definição do conceito. A ausência de trabalhos teóricos na literatura arquivística sobre a questão reflete-se, em certa medida, nas definições encontradas.

Ainda com bases na Biblioteconomia e reconhecendo as diferenças que essas duas disciplinas apresentam, a falta de comunicação interdisciplinar da classificação de documentos em arquivística com outras áreas do conhecimento, principalmente a Filosofia, impossibilita alcançar um arcabouço teórico-metodológico próprio da disciplina. A complexidade da operação de classificar documentos de arquivo e o quão fundamental essa operação é para a gestão arquivística parecem ainda escassos de uma solidez teórica e tendem por basear-se somente nos poucos princípios arquivísticos já consolidados - o de respeito aos fundos e o da ordem original.

\section{PRINCÍPIOS NORTEADORES NO PROCESSO DE CLASSIFICAÇÃO}

As atividades de arquivo têm por objetivo gerir um conjunto de informações produzidas por um organismo ou uma pessoa em torno das suas atividades que estão atreladas à missão e função ou à vida pessoal. Ao se pensar nas funções criação, classificação, avaliação, descrição e conservação, o arquivista deverá reconhecer o fundo de arquivo como a unidade central dessas funções.

$\mathrm{Na}$ tentativa de apresentar uma fundamentação teórico-metodológica do processo classificatório, é necessário discutir os dois princípios básicos inerentes aos documentos de arquivo, o princípio da proveniência (ou respeito aos fundos) e o princípio da ordem original, que têm servido, principalmente, para definir as estratégias de classificação. 
Natalis de Wailly, em meados do século XIX, redigiu uma circular para o Ministério do Interior onde atuava como chefe da Seção Administrativa dos Arquivos Departamentais. O documento, segundo Duchein (1986, p. 15), foi a "certidão de nascimento da noção de fundos de arquivos", em que consta "(...) agregar os documentos por fundos, isto é, reunir todos os títulos (documentos) provenientes de um corpo, de um estabelecimento, de uma família ou de um indivíduo, e dispor segundo uma determinada ordem os diferentes fundos (...)". Assim deu-se uma personalidade disciplinar própria aos arquivistas, criando-se uma nova forma de agrupar os documentos até então classificados por assunto ou por tema e evitandose graves erros. (ROUSSEAU; COUTURE, 1998, p. 80).

Para Rousseau e Couture (1998, p. 73), o princípio da proveniência é a lei que rege todas as atividades, além de ser a base teórica da arquivística. O fundo de arquivo, unidade de base em arquivística, é constituído e tem plena existência no respeito a esse princípio, no que diz respeito ao tratamento dos arquivos, qualquer que seja sua origem, idade, natureza ou seu suporte.

$\mathrm{Na}$ abordagem canadense, o princípio da proveniência é definido em dois graus: 1 - a proveniência está atrelada ao respeito à entidade que constitui o fundo de arquivo. 2 - o respeito ou reconstituição da ordem que os documentos receberam dentro da entidade (fundo), caso a ordem primitiva tenha sido alterada. (ROUSSEAU; COUTURE, 1998, p. 82-83).

O primeiro grau indica o fundo de arquivo como uma entidade distinta. Ele ocorre quando se deixam juntos ou se agrupam, caso dispersos, todos os documentos produzidos e recebidos por um organismo ou pessoa no exercício de suas atividades e funções. Esse primeiro grau tem aplicação tanto nos arquivos correntes quanto nos arquivos permanentes. A importância de manter-se o respeito a esse primeiro grau está em conseguir-se conservar suas atividades administrativas de forma plena e conservar o valor de testemunho do documento. O segundo grau diz respeito ao exigir-se que todos os documentos de um fundo de arquivo tenham sua ordem mantida ou reconstituída, caso a ordem primitiva tenha sido alterada por qualquer razão. É nesse segundo grau que o plano de classificação desenvolvido na fase corrente, se mantido nas outras fases (intermediário e permanente), exerce um papel fundamental ao refletir-se sobre os princípios de respeito aos fundos e ordem 
originais e manterem-se esses mesmos princípios.

A vantagem de se aplicar o princípio da proveniência, de manter a ordem original e o fundo arquivístico, é a de ser ele o único meio de garantir, segundo Rousseau e Couture (1998, p. 85), a integridade administrativa dos arquivos de uma entidade e manter o pleno valor de testemunho dos documentos de um fundo de arquivo. Como se não o bastante, há diversas vantagens, identificadas por diferentes autores, quanto ao respeito à proveniência dos fundos. Entre essas vantagens, a de permitir em primeiro lugar ter em conta a natureza dos documentos, pois, se os arquivos são o produto das atividades de um organismo ou de uma pessoa, os documentos que o compõem foram produzidos para responder a objetivos específicos, no âmbito de suas funções e atividades. Outra vantagem é que a aplicação do princípio da proveniência e o seu resultado - o fundo de arquivo leva os profissionais arquivistas a tratá-los como conjuntos documentais em vez de peças documentais, evitando-se, assim, interpretações ou qualquer subjetividade que a esses conjuntos possam estar associadas.

A aplicação desse princípio favorece também a recuperação da informação. Conhecer o organismo produtor, sua missão, atividades, funções, estilo de gestão e as relações existentes entre esses componentes são fatores que facilitam a recuperação da informação contida nos documentos. Porém, neste caso, isso só é possível se o fundo tiver sido respeitado. Respeitar o princípio da proveniência é maximizar o processo de gestão dos arquivos e, por fim, eliminar qualquer possibilidade de dispersão dos documentos.

No Brasil, o Dicionário Brasileiro de Terminologia Arquivística identifica o princípio da proveniência.

\footnotetext{
Segundo o qual os arquivos de uma mesma proveniência não devem ser misturados com os de diferente proveniência: este princípio inclui por vezes o princípio pela ordem original e define o princípio da ordem original como segundo o qual os arquivos de uma mesma proveniência devem conservar a organização estabelecida pelo organismo de origem. (ARQUIVO NACIONAL, 2005, p. 136-137).
}

Para Bellotto (2004, p. 130), o princípio da proveniência e da ordem original são dois desdobramentos do respeito aos fundos. Segundo a autora, o princípio da proveniência consiste em respeitar o órgão do produtor, enquanto a ordem original 
consiste em seguir a sequência original das séries, mesmo que alteradas com as eliminações decorrentes da aplicação das tabelas de temporalidade. E ainda explica que a ordem original não consiste apenas em manter a ordem física que os documentos mantinham no arquivo corrente, mas respeitar a organicidade, característica do documento de arquivo, definida por ela como "a observância do fluxo natural e orgânico com que foram produzidos e não propriamente nos detalhes ordenatórios de seu primeiro arquivamento".

Segundo Sousa, o modelo arquivístico atual não consegue dar conta das mudanças e transformações (criação, extinção, transferência e modificação das missões, funções, atividades e responsabilidades) sofridas pelas organizações atuais, visto que, para alguns autores, o conceito do princípio da proveniência deveria ser revisto diante da nova realidade das instituições, inclusive, com 0 advento dos documentos eletrônicos, importa que se analise mais atentamente o conceito de "fundo", que é "dependente e tributário do princípio da proveniência, aquele só existe quando o princípio foi aplicado". (SOUSA, 2004, p. 127).

O que de fato se configura como fundo? Como já citado pelo autor, atualmente as organizações ganham status de criada, desativada, extinta, reativada, realocada, transformada, o que torna essa pergunta um tanto quanto apropriada. Até hoje, desde 1977, Michel Duchein foi o único que melhor definiu e sistematizou o conceito de fundo de arquivo. Ele definiu cinco critérios a serem observados.

\begin{abstract}
1) Para produzir um Fundo de arquivo no sentido que o arquivista dá a este termo um organismo que seja público ou privado deve possuir um nome e uma existência jurídica própria resultante de uma ata, lei, decreto, etc. preciso e datado. 2) Deve possuir atribuições precisas e estáveis, definidas por um texto tendo valor legal e regulamentar. 3) A sua posição no seio da hierarquia administrativa deve ser definida com precisão pela ata que lhe deu origem em particular a sua subordinação a outro organismo de nível mais elevado deve ser claramente conhecido. 4) Deve ter chefe responsável, beneficiando do poder de decisão correspondente ao seu nível hierárquico, ou seja ele deve tratar dos trabalhos da sua competência sem tê-los que submeter automaticamente por decisão a uma autoridade superior. 5) A sua organização interna deve, tanto quanto possível, ser conhecida e fixada num organograma. (DUCHEIN, 1986, p. 21).
\end{abstract}

Consequências na aplicação dos referidos critérios:

1- Separa as divisões ou secções internas de um organismo que não respondam às condições requisitadas para produzir um Fundos de arquivo; 
2- Todo organismo possuindo uma existência jurídica e um nível de competências própria produz um Fundos de arquivo, mesmo se está subordinado a outro organismo de nível mais elevado. 3- Os órgãos locais dependentes de um organismo central produzem Fundos de arquivos que Ihes são próprios; 4- Por fim parece inevitável introduzir em Arquivologia uma noção nova: aquela de hierarquia de Fundos dos organismos produtores, provocando a subordinação de certos Fundos em relação a outros. (DUCHEIN, 1986, p. 21).

Duchein (1986, p. 21) também explica as variações de competências que os organismos produtores sofrem ao longo do tempo, Assim, para os casos de supressão, quando um organismo tem alguma ou algumas das suas atividades extintas; e criação de competências, quando são incorporadas novas atividades. Existem, ainda, os casos de transferência de competências (misto), quando as atribuições são transferidas de um organismo para outro. Por último, os casos de competências temporárias, quando são criadas algumas atribuições para atendimento a alguma demanda do organismo, embora, depois, essas atribuições sejam suprimidas.

Os parâmetros definidos pelo autor espelham e auxiliam na aplicação do conceito de fundo para a realidade dos organismos da administração pública brasileira, principalmente na instituição onde está se desenvolvendo esta pesquisa. O fundo Comando da Aeronáutica está sob processo de reestruturação, sendo necessária uma análise minuciosa com base em Michel Duchein para se definirem conceitos e para o direcionamento quanto ao tratamento arquivístico dos documentos acumulados dos "minifundos" pertencentes ao COMAER. Sem dúvida, a classificação dos documentos é a atividade primordial, fundamental, para gerenciar essa nova realidade.

Além do princípio de respeito aos fundos, que envolve proveniência e ordem original, não menos importante é identificar o princípio da organicidade, definido pelo Dicionário Brasileiro de Terminologia Arquivística (ARQUIVO NACIONAL, 2005, p. 127) como a "relação natural entre documentos de um arquivo em decorrência das atividades da entidade produtora" como um dos elementos norteadores da classificação dos documentos. Considera-se que os pilares da doutrina arquivística são: informação indissolúvel, meio documental no qual as informações estão vinculadas, suporte, proveniência e vínculo arquivístico. É importante identificar a 
gênese e a função dos documentos, desde a sua razão de ser até a sua destinação final, como afirma Bellotto (2014, p. 331).

\begin{abstract}
Autenticidade, confiabilidade, integridade, permanência é o que se espera dos documentos de arquivo como garantia de cidadania, de governabilidade, de entendimento e de permanência do respeito aos direitos e deveres assumidos entre governantes e governados, na esfera pública, ou mesmo nos microcosmos das organizações e entidades privadas.
\end{abstract}

O documento de arquivo tem sua especificidade identificada na relação entre produtor, contexto, gênese e função. Suas principais características são valor probatório e ser testemunho/informação. Além disso, possui vínculo arquivístico entre ele e os demais documentos do seu conjunto ligados à entidade produtora.

As mais importantes características do documento de arquivo são o princípio da proveniência e o princípio da organicidade, visto que a proveniência está ligada à relação entre produtor, recebedor e acumulador, e a organicidade, à coerência lógica e orgânica no contexto de produção, sendo o vínculo aos outros documentos do mesmo conjunto. E esse vínculo é denominado vínculo arquivístico. (BELLOTTO, 2014, p. 332).

Entende-se que um documento de arquivo origina-se do exercício de atividades atreladas a funções de uma organização. Esse documento abarca informações que devem ser controladas, preservadas e acessadas para a continuidade das atividades.

Dessa forma, a classificação - função primordial da gestão de documentos só será melhor desenvolvida ante as mencionadas reflexões sobre os conceitos e princípios arquivísticos, principalmente os da proveniência e ordem original organicidade -, visto que, o elo que os documentos de arquivo possuem, ou seja, a relação orgânica ou o vínculo arquivístico, "trata(-se) da conexão lógica e formal que une os documentos de um mesmo conjunto." (BELLOTTO, 2014, p. 332), características estas que podem ser materializadas no plano de classificação.

\title{
4 CONSIDERAÇÕES FINAIS
}

Ao analisar a origem da formação do conceito de classificação, constatou-se 
que sua construção entre seres e saberes foi consolidada por meio de diversas ciências, principalmente pela Filosofia. Mesmo com o surgimento da Teoria da Classificação, verifica-se que o processo classificatório em arquivística carece de um diálogo ou relação com as outras áreas do conhecimento, o que limita uma operação tão difícil e imprescindível para o saber e fazer arquivístico a um objeto de estudo e resulta na carência de um arcabouço teórico-metodológico próprio da área, notado na prática.

O surgimento das ferramentas teóricas na área, como o princípio de respeito aos fundos e da ordem original, simboliza uma transição importante nas bases e nas práticas de classificação de documentos de arquivo. A prática parece deixar de ser meramente intuitiva e passa a estudar mais e aprofundar as particularidades do objeto. A classificação de documentos de arquivo ganha fundamentação teóricometodológica e desenvolve-se de forma contínua e evolutiva.

No entanto, segundo Sousa (2004, p. 140), a trajetória ainda é extensa. Mesmo com o avanço de pensamentos e estudos do processo classificatório na Arquivologia, em uma reflexão sobre essas atividades constata-se que não houve ainda um preenchimento de várias falhas. "Onde a Teoria da Classificação entra nesse processo? Quais são as especificidades do objeto a classificar (o documento arquivístico)? Como coletar as informações necessárias para a elaboração de planos de classificação? Como analisar essas informações?"

$\mathrm{Na}$ análise desses questionamentos, comprova-se a necessidade de os profissionais da área aprofundarem as investigações nos processos de classificação de documentos, relacionando e assimilando os subsídios da Filosofia e da Teoria da Classificação para o estabelecimento de uma fundamentação teórica da classificação em arquivos, ao identificarem sua relação orgânica, reconhecerem os princípios arquivísticos respeitados internacionalmente e envoltos no processo classificatório, e, por fim, a construção de uma metodologia consistente para este processo tão significativo do saber arquivístico.

\section{REFERÊNCIAS}

ARQUIVO NACIONAL (Brasil). Dicionário brasileiro de terminologia arquivística. 
Rio de Janeiro: Arquivo Nacional, 2005.

BELLOTTO, Heloísa Liberalli. Arquivos permanentes: tratamento documental. 2. ed. Rio de Janeiro: FGV, 2004.

BELLOTTO, Heloísa Liberalli. Da gênese à função: $\mathrm{O}$ documento de arquivo como informação e testemunho. In: BELLOTTO, Heloísa Liberalli. Arquivo: estudos e reflexões. Belo Horizonte: UFMG, 2014, p. 329-344.

DAHLBERG, Ingetraut. Teoria da classificação, ontem e hoje. In: CONFERÊNCIA BRASILEIRA DE CLASSIFICAÇÃO BIBLIOGRÁFICA. Rio de Janeiro, 1979. Anais [...]. Rio de Janeiro: IBICT, 1979.

DEWEY, Melvil. Dewey decimal classification and relative index. 22. ed. Dublin, Ohio: OCLC, 2003.

DUCHEIN, Michel. O respeito aos fundos em arquivística: princípios teóricos e problemas práticos. Arquivo \& Administração, [S.I.], v. 10-14, n. 2, p. 1-16, 1986. Disponível em: http://www.brapci.ufpr.br/brapci/v/a/11453. Acesso em: 27 jul. 2017.

FERNANDEZ, Rosali P. Classificação: um processo fundamental da natureza humana. In: CONFERÊNCIA BRAŞILEIRA DE CLASSIFICAÇÃO BIBLIOGRÁFICA. Rio de Janeiro, 1979. Anais [...]. Rio de Janeiro: IBICT, 1979. p. 254-268.

FOUCAULT, Michel. As Palavras e as Coisas. São Paulo: Martins Fontes, 1995.

KUMAR, Krishan. Theory of Classification. New Delhi: Vikas, 1988.

POMBO, Olga. Da classificação dos seres à classificação dos saberes. Revista da Biblioteca Nacional de Lisboa, n. 2, p. 1-15, 1998. Disponível em: http://www.educ.fc.ul.pt/hyper/resources/opombo-classificacao.pdf. Acesso em: 20 mar. 2010.

ROUSSEAU, Jean-Yves; COUTURE, Carol. Os fundamentos da disciplina arquivística. Lisboa: Publicações Dom Quixote, 1998.

SCHELLENBERG, Theodore Roosevelt. Arquivos modernos: princípios e técnicas. 6. ed. Rio de Janeiro: FGV, 2006.

SOUSA, Renato Tarciso Barbosa. Classificação em arquivística: trajetória e apropriação de um conceito. São Paulo: USP, 2004.

Recebido em 31/10/2019.

Aceito em 04/12/2019. 